\title{
EL EFECTO DE LOS PREVERBIOS SOBRE UIN VERBO DE MANERA DE MOVERSE LATINO ${ }^{1}$
}

\section{ANA LORENA NIETO MANINI}

Universidad Nacional de San Juan / Universidad de Salamanca alorenanietom@gmail.com / alnietomanini@usal.es

\section{Introducción}

El presente estudio tiene por objetivo establecer la diferencia en el significado y comportamiento gramatical del Verbo de Manera de Moverse salire ('saltar') cuando aparece en forma simple y cuando lo hace con preverbios añadidos -forma compuesta. Este verbo es claramente Verbo de Manera de Moverse ya que salire se define por el tipo de movimiento en sí.

Se constituye un corpus para salire considerando la obra completa del poeta latino Ovidio conformado a partir de la base de datos del programa computacional Diógenes (PHI). Formamos un grupo de datos total de setenta y un casos, según la cantidad de veces que aparece tanto en forma simple $(10 \text { casos })^{2}$ como en forma compuesta (61 casos), con preverbios añadidos. Estos son:

\begin{tabular}{l|l|l}
\hline Preverbios & Cantidad de casos & Referencias \\
\hline ad- & 4 & Met. 6, 107; Met. 11, 526; Fast. 3, 591; Fast. 5, 612. \\
\hline de- & 14 & $\begin{array}{l}\text { Am. 3, 7, 81; Ep. 15, 172; Ars 1, 560; Ars 3, 22; Met. 1, 674; Met. } \\
\text { 3, 681; Met. 4, 353; Met. 7, 378; Met. 10, 722; Met. 12, 129; Fast. } \\
\text { 2, 111; Fast. 2, 588; Fast. 3, 866; Fast. 6, 422. }\end{array}$ \\
\hline di- & & Am. 2, 25; Met. 2, 260; Met. 5, 173; Met. 12, 488; Tr. 4, 6, 20. \\
\hline ex- & 5 & $\begin{array}{l}\text { Met. 3, 670; Met. 5, 35; Met. 6, 77; Met. 6, 696; Met. 7, 320; Met. } \\
\text { 9, 314; Met. 12, 252; Met. 14, 406; Fast. 3, 643; Fast. 5, 16. }\end{array}$ \\
\hline in- & 10 & Met. 8, 142; Met. 8, 367; Met. 11, 731; Met. 12, 346; Tr. 1, 4, 8. \\
\hline pro- & 5 & $\begin{array}{l}\text { Ars 3, 607; Met. 6, 260; Met. 6, 658; Met. 7, 573; Met. 11, 385; } \\
\text { Met. 12, 390; Met. 15, 272; Fast. 2, 228; Fast. 2, 471; Fast. 3, 452; } \\
\end{array}$ \\
& 13 & Fast. 3, 842; Fast. 4, 796; Fast. 6, 494. \\
\hline re- & 3 & Met. 3, 677; Met. 6, 374; Met. 12, 481. \\
\hline trans- & 7 & $\begin{array}{l}\text { Fast. 2, 134; Fast. 3, 70; Fast. 4, 727; Fast. 4, 843; Tr. 4, 3, 8; Pont. } \\
1,2,144 ; \text { Pont. 1, 5, 76. }\end{array}$ \\
\hline
\end{tabular}

Tabla 1: Preverbios utilizados en los compuestos de salire 
El análisis se hace teniendo en cuenta conceptos de lingüística, de carácter funcional y cognitivo, correspondientes a los distintos niveles de la lengua. Se observa el carácter télico ${ }^{3}$ o atélico de la cláusula según los argumentos que acompañen a salire, comprobando que los Verbos de Manera de Moverse simples por sí solos, extraídos de contexto, sí pueden definirse generalmente como atélicos y sus compuestos como télicos, pero resulta que no es una exigencia y necesidad intrínseca cuando están contextualizados. Esta hipótesis primera no se aplica con el verbo que estudiamos por su contenido semántico: salire, por el tipo de movimiento que realiza, puede definirse como télico en su forma simple, y comprobaremos si este carácter se altera o no con la añadidura de preverbios, al contrario de lo que se presupone acerca de los Verbos de Manera de Moverse.

El efecto que los preverbios ocasionan en los Verbos de Manera de Moverse no siempre es de carácter resultativo ${ }^{4}$, pero sí determina su telicidad o atelicidad siempre en contexto, según los complementos que contenga. Por lo tanto el resultado de la añadidura de preverbios, de esta lexicalización común en la lengua latina, no determina obligatoriamente la conversión en télico de un Verbo de Manera de Moverse como es salire, el cual en su forma simple ya es télico.

Es interesante notar que esta diferencia entre lenguas de marco por satélite a una lengua de marco verbal trae dificultades a los traductores, tal como del latín al castellano. Además, aclaramos que la elección de las traducciones ha sido realizada teniendo en cuenta la presencia de versos numerados, más que por otra variable.

\section{Breve introducción teórica ${ }^{5}$}

Salire se configura como un Verbo de Manera de Moverse que indica el Trayecto mediante complementos adverbiales, es decir, satélites o preverbios. Siguiendo a MORIMOTO (2001), incluimos salire dentro de los VMM-E, ya que implica una manera de moverse determinada y específica definida por el tipo de movimiento en sí y ocasiona influencia en el medio exterior. Expresa la manera cómo lo realiza y se combina en su forma compuesta con distintos preverbios (satélites) latinos. La traducción al español suele recoger la semántica de los preverbios mediante complementos adverbiales, configurándose según la distinción inicial hecha por TALMY $(1985,2003)$ como verbframed languages.

Examinamos si salire aparece en latín solo (su forma simple) o con algún agregado locativo -preverbio, sintagma preposicional, expresión adverbial- que indique dirección de Origen, Vía o Meta del movimiento. Es decir, nos proponemos diferenciar si el satélite nos indica desde dónde -unde?-, por dónde -qua?- o hacia dónde -quo?- se realiza el movimiento de saltar, de acuerdo con las ventanas de atención (windows of attention) que abre el hablante según qué desea que el lector/oyente focalice. 


\section{Presentación de salire}

Hemos considerado y definido el verbo salire como Verbo de Manera de Moverse Externo a partir de tres rasgos establecidos por MORIMOTO (2001: p. 50): está presente el desplazamiento, la trayectoria es indeterminada y sí tiene manera de movimiento.

La primera definición que encontramos del verbo la brinda el diccionario de la Oxford Claredon Press (Lewis $\mathcal{E}$ Short, 1891) ofreciendo la acepción en sentido propio (to leap, spring, bound, jump). Por otro lado, el OLD -Oxford Latin Dictionary- (s.v.) lo define como transitivo e intransitivo. La primera definición la brinda como un verbo que indica 'saltar' y que en poesía suele tener como Figura principal a objetos inanimados. Luego en un sentido más metafórico, significa el movimiento repentino de partes del cuerpo, especialmente bajo emociones. En tercer lugar, define su uso para fluidos líquidos, también metafóricamente. Y en cuarto lugar, solo con uso transitivo, para animales masculinos en el sentido de montar. De estos cuatro tipos de usos de salire aparecen en nuestro corpus solo los tres primeros. Podemos aunar las acepciones de los dos diccionarios diciendo que el verbo salire se utiliza tanto para el uso real del verbo como para un uso metafórico, con Figuras tanto animadas como inanimadas, en aspecto total o metonímico (partes del cuerpo).

\section{Análisis de salire}

En salire analizamos los eventos de movimiento a partir de los siguientes elementos: quién (es decir qué Figura) realiza el desplazamiento (mediante el VMM-E salire) en el espacio exterior (Trayectoria) y a partir de qué elementos (Complementos Circunstanciales, Complementos Directos y Preverbios) cambia el carácter de una cláusula (sintáctico: transitividad; semántico: telicidad) y cómo se define dicho desplazamiento (ventanas de atención).

\subsection{La Figura desde el plano sintáctico y semántico}

En todos los casos relevados encontramos Figuras que realizan la acción (TALMY 1985: p. 61), las cuales se definen de la siguiente manera: The basic motion event consists of one object (the 'Figure') moving or located with respect to another object (the reference-object or 'Ground'). Es decir que un evento de movimiento consiste en que un objeto (la Figura) se mueve o cambia de locación con respecto a otro objeto (el objeto-referente, o Fondo).

En todos los casos encontrados con el verbo salire, la Figura aparece explícita o elidida; no encontramos casos impersonales con este verbo.

Ovidio tiene una gran preferencia por utilizar la Figura de manera explícita (sesenta y siete casos) en las cláusulas con verbo salire en forma simple o compuesta. Solo en cuatro cláusulas el sujeto sintáctico, la Figura, está bajo el recurso de la elipsis. Todos estos casos se corresponden por contexto con una Figura humana. 
Con respecto al nivel semántico, el verbo salire prefiere la utilización de Figuras más prototípicas en la agentividad, es decir, con mayor control, volición e intención en la acción y mayor empatía con dichos rasgos. Pero si bien es una generalidad, no es la totalidad, pues hay casos (menores, pero existentes) donde la Figura es miembro periférico en relación con el carácter de agentividad, al ser un elemento inanimado y no humano. En estos casos la Figura se encuentra personificada, o realiza la acción por el efecto de una causa explícita o que se le adjunta desde el cotexto. Muchas de estas cláusulas con Figuras personificadas aparecen con usos metafóricos del verbo. Por último, utiliza menos Figuras de rasgos animales o divinos/semidivinos.

\subsection{Trayectoria}

La Trayectoria (Path) es definida como el itinerario, es decir, el recorrido que realiza la Figura con respecto al Fondo. Es uno de los elementos centrales que TALMY (2003) considera dentro del evento de movimiento.

En todo evento de movimiento, el hablante enunciador del discurso crea windows of attention, es decir, ventanas de atención, focalizando así una información y omitiendo otra, gapping.

La mitad de los casos en forma simple de salire (es decir, cinco de los diez casos) no presentan Complementos Circunstanciales de Lugar que indiquen Trayectoria, pero encontramos la misma cantidad (cinco casos) que sí se estructuran con Complementos Circunstanciales que indiquen Trayectoria, con la ventana de atención puesta en la Vía o en la Meta.

En las formas compuestas de salire tenemos 61 casos conformados por preverbios. Se resumen los rasgos en el cuadro a continuación:

\begin{tabular}{|l|c|c|c|c|}
\hline & Origen & Vía & Meta & Telicidad \\
\hline$A d-(4)$ & - & - & + & $+3 ;-1$ \\
\hline$D e-(14)$ & + & - & $(+C T)$ & + \\
\hline$D i(s)-(5)$ & + & - & + & + \\
\hline$E x-(10)$ & + & $(1)$ & + & $+9 ;-1$ \\
\hline In-(5) & - & - & + & + \\
\hline Pro-(13) & $(+$ CT) & - & + & $+8 ;-5$ \\
\hline $\operatorname{Re}-(3)$ & - & - & + & $+1 ;-2$ \\
\hline Trans-(7) & + & $(+C T)$ & + & $+4 ;-3$ \\
\hline
\end{tabular}


Para no extendernos en la nota breve, detallaremos las conclusiones a las que se llega según el análisis realizado; explicaremos los rasgos resumidos en este cuadro.

Consideramos que el preverbio ad- por sí solo favorece la telicidad en la cláusula, pero existen cuatro casos en los cuales esto no siempre es así. El satélite ad- se configura como un preverbio que implica telicidad con el verbo salire, pero no en todas las cláusulas: si no lo acompañan complementos que delimiten el principio o fin, el preverbio por sí solo afecta a la telicidad propia de este tipo verbal.

El preverbio de- en cuanto a estadística cuantitativa es el más elegido por Ovidio. El poeta es consciente del significado de este preverbio y decide acentuarlo en la mayoría de los casos con Complementos de Trayectoria, unos pocos que indican Origen, y los más que indican Meta. Por lo tanto, la adhesión del preverbio tiene por efecto en salire, junto a los Complementos de Trayectoria, el mantener el carácter de telicidad en dichas cláusulas.

Con respecto a di(s)-, notamos en el análisis que este preverbio no transitiviza el uso de salire como tampoco altera su telicidad, ya que todos los compuestos continúan siendo télicos. Ovidio acentúa la manera en la que se realiza el verbo con significado abrupto en el sentido de contexto hostil a partir de las Figuras que realizan la acción.

El preverbio ex- combinado con el verbo salire mayoritariamente muestra en Ovidio la presencia de la telicidad en sus cláusulas. Estas siempre aparecen acompañadas de Complementos de Trayectoria, sean propios de las cláusulas, o de frases anteriores o siguientes. Creemos que, si este verbo compuesto aparece con Complemento de Trayectoria que indica Vía, la telicidad se ve alterada porque no establece ni principio ni fin de la acción, más allá del carácter semántico del preverbio, por ser un solo caso particular con información modificada o disputada, que es el siguiente:

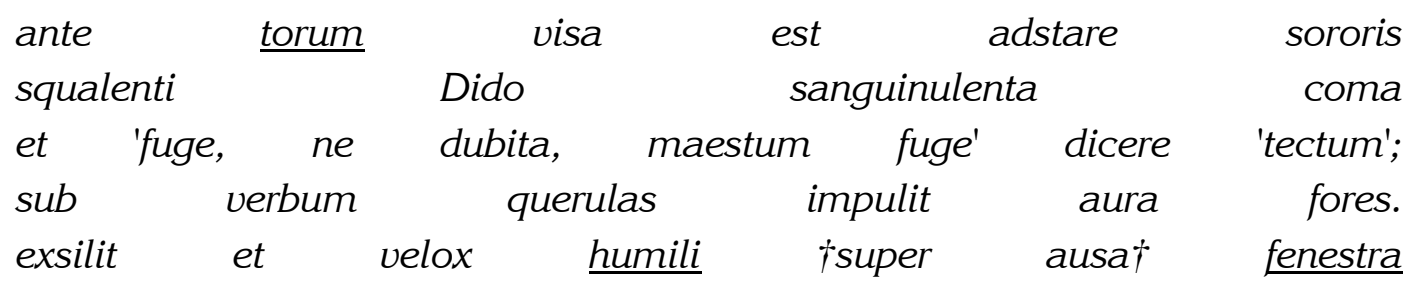
se iacit (audacem fecerat ipse timor)

Delante del lecho de Ana le pareció a esta que se levantaba Dido ensangrentada y con el pelo desgreñado, y que le decía: "Huye, no lo dudes, huye de una casa entristecida”. Tras estas palabras, la brisa impulsó la puerta quejumbrosa. Se levantó de un salto y se lanzó rápidamente por una ventana baja, a ras de tierra: el propio miedo, la había hecho atrevida. (Fas. 3, 639-644) ${ }^{6}$

Ovidio utiliza el preverbio in- con el verbo salire siempre en sentido local, dando el significado de penetración e ingreso hacia determinado lugar, que es la Dirección a la 
que se dirigen las Figuras a partir del Dativo regido, en lo cual innova para su época. Intensifica el valor télico del verbo y no lo transitiva.

El preverbio pro- es uno de los más utilizados en combinación con el verbo salire en Ovidio por frecuencia de uso. Si bien generalmente perfectiviza acciones, esto no sucede siempre. Aunque en menor ocurrencia no dejamos de lado dicho acontecimiento lingüístico, ya que la intención del autor es consciente y se manifiesta en la forma verbal que elige y qué complementos quiere que acompañen a cada cláusula.

El preverbio re- junto a salire en Ovidio no marca siempre la telicidad de la cláusula, sino que, al tener un doble uso semántico, puede mantener la telicidad de la cláusula o puede alterarla y hacerla atélica, cuando tiene el significado de repetición.

Por último, con respecto a los casos que escribe Ovidio combinando el verbo salire con el preverbio trans-, podemos concluir que sus utilizaciones son "ambiguas" en cuanto a los análisis que esperaríamos encontrar, debido a su uso escaso o innovador: observamos que la añadidura del preverbio trans- altera el aspecto propio de telicidad del verbo, y al ser utilizado en cláusulas que no tienen por intención marcar el principio o fin de la acción, comprobamos una vez más que este aspecto puede definirse a partir de los complementos que acompañan la cláusula y podemos comprender el objetivo del autor en un texto literario.

\section{Conclusiones}

Cuando se trata de salire en forma simple, comprobamos que el poeta elige no utilizar mucho este verbo sin preverbios añadidos. Solo nos encontramos con 10 (diez) casos de los cuales la mitad aparece sin complementos que indican trayectoria y la otra mitad, con ellos. Con respecto a salire en forma compuesta, no comprobamos la hipótesis de que el preverbio altera la telicidad en los Verbos de Movimiento, porque este verbo por sí solo en forma simple ya es télico. Cuando se le añaden los preverbios de-, dis- e in-, las cláusulas mantienen en todos sus usos la telicidad inherente al verbo. Pero el uso de los otros preverbios muestra una modificación de la gramática a priori que realiza Ovidio, innovando en la forma lingüística como producción artística.

El objetivo principal de nuestro trabajo ha sido demostrar los efectos que ocasionan los preverbios sobre todo en cuanto al rasgo de telicidad. Se postula por regla general que algunos verbos simples (en nuestro caso, salire) tienen carácter atélico y los compuestos con preverbios añadidos cambian a télicos. Pero sucede que no existe gramática a priori y en este análisis de Ovidio lo demostramos, ya que salire en forma simple ya implica un movimiento télico en sí mismo, y su forma compuesta aparece tanto en forma télica como atélica. No es regla general, ya que lo que incide en la telicidad de las cláusulas son los datos cotextuales y contextuales de la historia que se cuenta. 
Por último, destacamos la importancia del trabajo de los traductores. Es difícil determinar en qué cláusulas el poeta tan lejano a nosotros ha establecido determinada estructura o cuál otra, pero hemos mostrado que hay marcas textuales, cotextuales y contextuales que si bien propician la creatividad del traductor limitarían de algún modo ciertas traducciones, las cuales deben estar siempre atentas a dichas marcas (tipos de Figura desde el nivel semántico, utilización de preverbios en contextos donde no los esperamos, entre otros).

Pretendemos que este estudio sea un humilde aporte para la tarea de traducción de textos latinos y ayude a la reflexión sobre las mismas, en tanto notemos también, a partir de la investigación, la dimensión ideológica a la que pertenece el traductor y su grupo editorial. Entendemos que, a partir del análisis, funcionalidad y traducción de los preverbios, podemos cuestionar y, muchas veces, predecir por qué en la misma cláusula continúa un complemento de lugar, o de manera, u objeto directo, entre muchos otros.

\section{Bibliografía}

LEWIS, T. C. \& SHORT, C. (1891). A Latin Dictionary. Oxford Clarendon Press. https://archive.org/stream/LewisAndShortANewLatinDictionary/lewisandshort\#page/n0/m ode/2up. [04 de agosto de 2021]

MORIMOTO, Y. (2001). Los verbos de movimiento. Visor Libros.

NiETO MANINI, A. (2018). El arte de volar en Ovidio: el efecto de los preverbios sobre un Verbo de Manera de Moverse. Argos, 41, e0001. https://doi.org/10.14409/argos.2018.41.e0001

Segura Ramos, B. (1988). Ovidio. Fastos. Gredos.

TALMY, L. (1985). Lexicalization patterns: semantic structure in lexical forms. En T. SHOPEN, Language, tipology and syntactic description (pp. 57-149). Cambridge University Press.

TALmy, L. (2003a). Toward a Cognitive Semantics. Volume I: Concept Structuring Systems. Cambridge MIT Press.

TALMY, L. (2003b). Toward a Cognitive Semantics. Volume II: Typology and process in concept structuring. Cambridge MIT Press. 


\section{Notas}

${ }^{1}$ El presente trabajo es un resumen de mi tesis de Licenciatura en Letras (2019 - UNSJ) y es una profundización del tema (efecto de los preverbios sobre un Verbo de Manera de Moverse en Ovidio), en este caso analizando el verbo salire, que surge como continuación/profundización del trabajo final de maestría en Filología Clásica (2018 - Usal), donde analicé el mismo tema con el mismo autor, pero en el verbo volare. Publicado como artículo en Argos, $n^{\circ} 41$. Por lo tanto se decide a partir de las observaciones realizadas por pares ciegos y comprendiendo su carácter innecesario, eliminar las partes teóricas repetidas que son funcionales para ambos verbos, e invitar a los lectores a remitirse al artículo anterior de Argos $\mathrm{n}^{\circ} 41$.

${ }^{2}$ Met. 3, 587; Met. 6, 381; Met. 6, 390; Met. 6, 559; Met. 10, 289; Met. 14, 543; Fast. 4, 805; Ib., 556; Ib., 597.

${ }^{3}$ Un predicado es télico cuando la acción que designa es vista desde su cumplimiento, desde su final. Su oponente, atélico, no presenta dicha característica (ÁLVAREZ HUERTA 2009: p. 136).

${ }^{4}$ Se utiliza el término "resultativo" como expresión equivalente a la limitación gramatical, es decir, al aspecto télico.

${ }^{5}$ Para la ampliación de la introducción teórica y de la bibliografía consultada, remitimos a los lectores al artículo publicado en Argos 41 titulado "El arte de volar en Ovidio: el efecto de los preverbios sobre un Verbo de Manera de Moverse".

${ }^{6}$ Trad.: Segura RAmOS, 1988. 